\title{
Time Course of Extracellular Dopamine and Behavioral Sensitization to Cocaine. II. Dopamine Perikarya
}

\author{
Peter W. Kalivas and Patricia Duffy \\ Alcohol and Drug Abuse Program and Department of Veterinary Anatomy, Pharmacology and Physiology, Washington \\ State University, Pullman, Washington, 99164-6520
}

\begin{abstract}
Cocaine was administered daily $(15 \mathrm{mg} / \mathrm{kg}$, i.p. $\times 1 \mathrm{~d}$ followed by $30 \mathrm{mg} / \mathrm{kg}$, i.p. $\times 5 \mathrm{~d}$ ) to produce behavioral sensitization. Using microdialysis in the ventral tegmental area and medial substantia nigra, the effect of repeated cocaine was examined on the extracellular levels of dopamine. One day after discontinuing repeated cocaine injections, an acute challenge with cocaine (15 $\mathrm{mg} / \mathrm{kg}$, i.p.) produced a significant elevation in extracellular dopamine compared to rats pretreated with daily saline ( $\times 6 \mathrm{~d})$. The augmentation in extracellular dopamine persisted longer than the sensitized behavioral response. In contrast, $14 \mathrm{~d}$ after discontinuing daily cocaine, the increase in extracellular dopamine produced by an acute cocaine challenge was not augmented, although behavioral sensitization was present. In separate animals, the basal concentration of dopamine in the ventral tegmental area/medial substantia nigra was measured by determining the concentration of dopamine at which no net flux occurred across the dialysis membrane in vivo. One day after discontinuing daily treatments, the basal level of extracellular dopamine in the cocaine pretreated rats was significantly elevated over the level in saline-pretreated animals (1.3 nM vs. $0.8 \mathrm{~nm}$ ). By $14 \mathrm{~d}$ after the last daily injection, the basal levels of dopamine were equivalent in cocaine- and saline-pretreated animals. It is concluded that daily cocaine injections produce a transient alteration in the regulation of somatodendritic dopamine release. While such changes are not responsible for the long-term behavioral sensitization produced by repeated cocaine administration, they may be involved in the initiation of behavioral sensitization.
\end{abstract}

IKey words: cocaine, dopamine, ventral tegmental area, sensitization, locomotion, dialysis]

Behavioral augmentation resulting from the repeated administration of psychostimulants is generally found to be associated with enhanced extracellular dopamine content in the striatum and nucleus accumbens (see Kalivas and Stewart, 1991, for review). As shown in the preceding report, the association between extracellular dopamine and behavior varies with the treatment regimen and the time course of drug withdrawal (Kalivas and Duffy, 1992). Nonetheless, there is a concurrence in the literature that behavioral sensitization that endures for weeks

\footnotetext{
Received Feb. 11, 1992; revised Apr. 28, 1992; accepted July 17, 1992

We thank Jenny Baylon for assistance in preparing the manuscript. The research was supported in part by U.S. Public Health Service Grants DA-03906 and MH 40817, and by Research Career Development Award DA-00158.

Correspondence should be addressed to Peter Kalivas, Ph.D., Department of VCAPP, Washington State University, Pullman, WA 99164-6520.

Copyright (C) 1993 Society for Neuroscience $0270-6474 / 93 / 130276-09 \$ 05.00 / 0$
}

or months after discontinuing daily psychostimulant administration is associated with an augmentation in extracellular dopamine content in axon terminal fields, such as the striatum and nucleus accumbens (Robinson et al., 1988; Akimoto et al., 1989, 1990; Kazahaya et al., 1989; Kalivas and Duffy, 1990; Pettit et al., 1990; Patrick et al., 1991). These findings argue that a change in dopamine release or reuptake in dopamine axon terminals is important in behavioral sensitization. While presynaptic regulation by other transmitters has becn postulated to play a role in altering axonal dopamine transmission (Benloucif and Galloway, 1991; Yoshikawa et al., 1991), it is also likely that alterations in the dopamine cell bodies may be critical. Pretreatment with the protein synthesis inhibitor anisomycin prevents the development of behavioral sensitization to amphetamine (Robinson, 1991), arguing for an alteration in perikarya. Furthermore, microinjection of amphetamine or opioids onto the dopamine cell bodies in the ventral mesencephalon, but not into the axon terminal fields, produces behavioral sensitization to a subseqent systemic drug challenge (Hitzemann et al., 1980; Dougherty and Ellinwood, 1981; Kalivas and Weber, 1988; Vezina and Stewart, 1990; Hooks et al., 1992). Finally, pretreatment of dopamine cell bodies with a $D_{1}$ antagonist or $\mathrm{GABA}_{\mathrm{B}}$ agonist prevents behavioral sensitization to systemic amphetamine or cocaine, respectively (Stewart and Vezina, 1989; Kalivas and Stewart, 1991).

Based upon the fact that drug action in the dopamine cell body region is important in the initiation of behavioral sensitization to psychostimulants, the present report measured extracellular dopamine content in the vicinity of dopamine neurons in the ventral mesencephalon using in vivo microdialysis. The dopamine perikarya in this region are topographically organized with respect to ascending projection fields (Fallon and Moore, 1978; Swanson, 1982). The more medial cells in the ventral tegmental area and medial substantia nigra project to limbic and cortical structures such as the ventral striatum, while the lateral substantia nigra projects more exclusively to the dorsal striatum. Because of this topography, dialysis probes were placed into the ventral tegmental area and medial substantia nigra (VTA/SN) to estimate extracellular somatodendritic dopamine levels from neurons projecting preferentially to the ventral striatum where the dialysis experiments in the accompanying article were conducted (Kalivas and Duffy, 1992).

\section{Materials and Methods}

Animal housing and surgery. Male Sprague-Dawley rats (Laboratory Animal Resource Center, Pullman, WA) were individually housed with food and water made available ad libitum. A $12 \mathrm{hr} / 12 \mathrm{hr}$ light/dark cycle was used with the lights on at $6: 30 \mathrm{hr}$. All injections of cocaine 


\begin{tabular}{|c|c|c|c|c|}
\hline \multirow[b]{2}{*}{ Group } & \multicolumn{4}{|c|}{ Treatment day } \\
\hline & 1 & $2-6$ & 7 & 20 \\
\hline 1 & Saline & Saline & Saline (7) & Saline (4) \\
\hline 2 & Cocaine & Cocaine & Saline (8) & Saline (6) \\
\hline 3 & Saline & Saline & Cocaine (6) & Cocaine (6) \\
\hline 4 & Cocaine & Cocaine & Cocaine (8) & Cocaine (8) \\
\hline 5 & Saline & Saline & Basal (7) & Basal (6) \\
\hline 6 & Cocaine & Cocaine & Basal (8) & Basal (8) \\
\hline
\end{tabular}

Days 7 and 20 were in the photocell/dialysis apparatus, and days 1-6 were in the home cage. On days 1,7 , and 20 the intraperitoneal dose of cocaine was $15 \mathrm{mg} /$ $\mathrm{kg}$, and on days $2-6$ it was $30 \mathrm{mg} / \mathrm{kg}$. "Basal" refers to studies where dopamine was titrated through the dialysis probe in vivo to determine extracellular dopamine content. The number of animals is shown in parentheses.

were made between 11:00 and 13:00 hr. Rats weighing between 260 and $320 \mathrm{gm}$ were anesthetized with Equithesin and mounted in a stereotaxic apparatus (David Kopf, Torrance, CA). A chronic unilateral dialysis guide cannula (20 gauge stainless steel, $14 \mathrm{~mm}$ long) was implanted $3 \mathrm{~mm}$ dorsal to the VTA/SN (A/P $2.6 \mathrm{~mm}, \mathrm{D} / \mathrm{V}-2.5 \mathrm{~mm}$, $\mathrm{M} / \mathrm{L} 0.7 \mathrm{~mm}$; relative to the interaural line according to the atlas of Pellegrino et al., 1979). The cannula was cemented into place by affixing dental acrylic to three stainless steel screws tapped into the skull. The wounds were sutured, and the rats were allowed a minimum of 1 week recovery prior to beginning experimentation.

Microdialysis. All microdialysis experiments were conducted as described in the accompanying article (Kalivas and Duffy, 1992). The dialysis probes were inserted through the guide cannulas into the VTA SN the night prior to the experiment. The next day, baseline samples (20 min each) were collected for $60-80 \mathrm{~min}$, then cocaine $(15.0 \mathrm{mg} / \mathrm{kg}$, i.p.) or saline $(1.0 \mathrm{ml} / \mathrm{kg}$, i.p.) was administered and six additional 20 min dialysis samples were obtained. Behavioral data were collected in 20 min intervals simultaneous with the dialysis samples. When the experiment was terminated, the dialysis probe was removed, and the animal returned to its home cage and killed within $7 \mathrm{~d}$ for histological verification of the dialysis probe placement (see below).

Treatment groups. Table 1 shows the treatment groups used. Groups I-4 were challenged after daily saline or cocaine with acute saline or cocaine injections, while groups 5 and 6 were examined for basal levels of extracellular dopamine after daily pretreatment with cocaine or saline. The rats were administered either daily saline $(1.0 \mathrm{ml} / \mathrm{kg}$, i.p. $\times 6 \mathrm{~d}$; groups 1,3 , and 5) or given cocaine $(15 \mathrm{mg} / \mathrm{kg}$, i.p.; groups 2,4 , and $6)$ on day 1 followed hy daily cocaine injections $(30 \mathrm{mg} / \mathrm{kg}$, i.p. $\times 5 \mathrm{~d})$ on days 2-6. In groups 1 and 2, the daily saline- and cocaine-pretreated animals were challenged with an acute saline injection $24 \mathrm{hr}$ (day 7) or 2 weeks (day 20) after discontinuing the daily treatment regimen. In groups 3 and 4 , the rats were challenged with acute cocaine $(15 \mathrm{mg} / \mathrm{kg}$, i.p.) on day 7 or day 20 . A single dialysis experiment was conducted in each rat; therefore, separate animals were used for each day.

In groups 5 and 6 (see Table 1), the basal concentration of extracellular dopamine was determined by adding dopamine to the dialysis perfusate at concentrations above and below the expected extracellular concentration $(0,1,3$, and $10 \mathrm{~nm})$ to generate a series of points that were interpolated to measure the concentration at which no net flux of dopamine occurred across the dialysis membrane (Lonroth et al., 1987; Parsons and Justice, 1991; Parsons et al., 1991; see accompanying article, Kalivas and Duffy, 1992).

Measurement of dopamine in dialysis samples. The collection of the dialysis samples and quantification of dopamine content were carried out as described in the accompanying article (Kalivas and Duffy, 1992).

Histology and data analysis. Rats were killed with an overdose of pentobarbital, and the location of the dialysis probes in the brain was histologically verified as described in the accompanying article (Kalivas and Duffy, 1992). In addition, some tissue sections (50 $\mu \mathrm{m}$ thick) were prepared for tyrosine hydroxylase immunocytochemistry as described elsewhere (Kalivas and Duffy, 1991).

The neurochemical and behavioral time course data were statistically evaluated using a two-way analysis of variance (ANOVA) with repeated measures over time. Dopamine content was normalized to percentage change from the average of three baseline samples for each experiment prior to statistical analysis. Post hoc evaluation of statistical differences
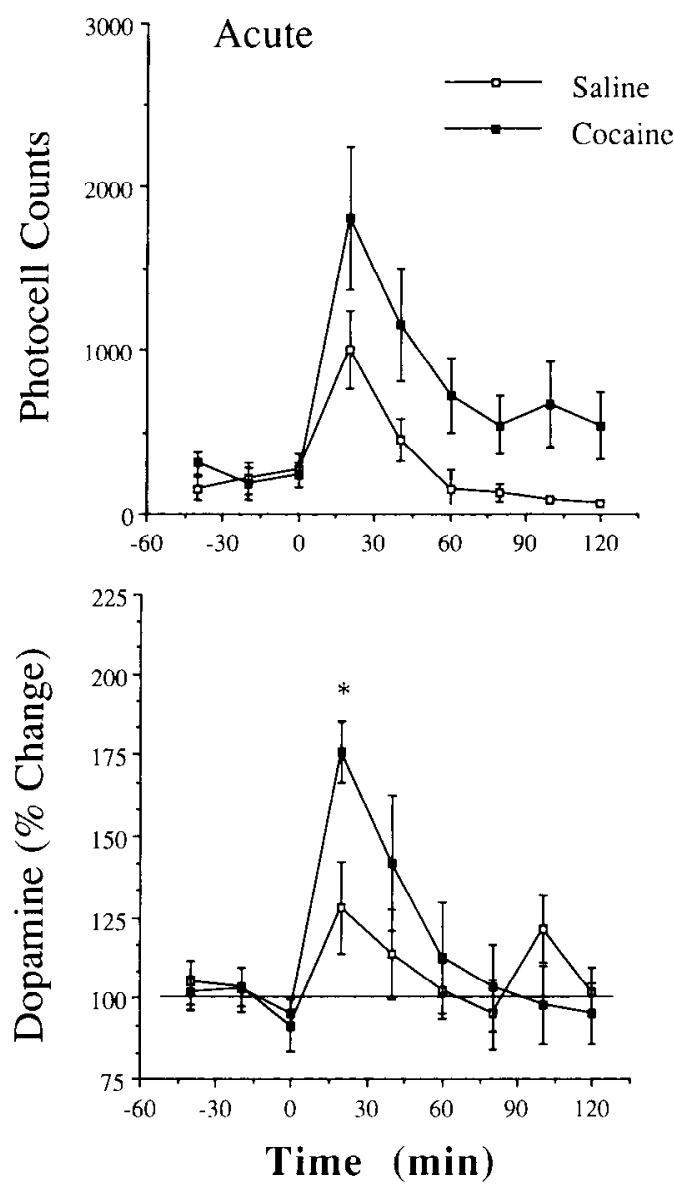

Figure 1. Effect of acute cocaine and saline on motor activity and extracellular dopamine in the VTA/SN. The data are the pooled response to saline $(N=11)$ or cocaine $(N=12)$ on days 7 or 20 from rats pretreated with daily saline in groups 1 and 3. For dopamine values, the data were divided by the average of the three baseline measurements obtained prior to injecting saline at time 0 . The basal values were not statistically different between the cocaine $(47 \pm 9 \mathrm{fmol} / \mathrm{min})$ and saline $(29 \pm 6 \mathrm{fmol} / \mathrm{min})$ pretreatment groups $(F=2.62, p=0.121)$. The data are shown as mean \pm SEM photocell counts or percentage change in dopamine. All data were evaluated using a two-way ANOVA with repeated measures over time. $F$ scores for behavior: treatment $F=4.96$, $p=0.044$; time $F=10.24, p<0.001$; interaction $F=0.80, p=0.601$. Dopamine $F$ scores: treatment $F-0.56, p-0.466$; time $F-1.65, p$ $<0.121$; interaction $F=2.34, p=0.024{ }^{*}, p<0.05$, comparing cocaine to saline pretreatment groups at each time using a least significant difference test (Milliken and Johnson, 1984).

was performed using a least significant difference test, as described by Milliken and Johnson (1984). To determine the concentration of no net flux of dopamine through the dialysis probe, regression analysis was performed and the basal concentration compared between cocaine and saline treatment groups using a two-tailed Student's $t$ test.

\section{Results}

Effect of acute cocaine and saline on extracellular dopamine. Figure 1 shows the response to acute cocaine $(15 \mathrm{mg} / \mathrm{kg}$, i.p.) or saline $(1.0 \mathrm{ml} / \mathrm{kg}$, i.p.) on motor activity and the extracellular concentration of dopamine in the VTA/SN. The data were pooled from rats challenged with saline or cocaine on days 7 or 20 after receiving daily saline injections (i.e., groups 1 and 3). Cocaine injection resulted in a significant decrease in extracellular dopamine concentration comparcd to salinc administration. Although a significant effect of treatment was produced on photocell counts, there was not a significant difference at individual 

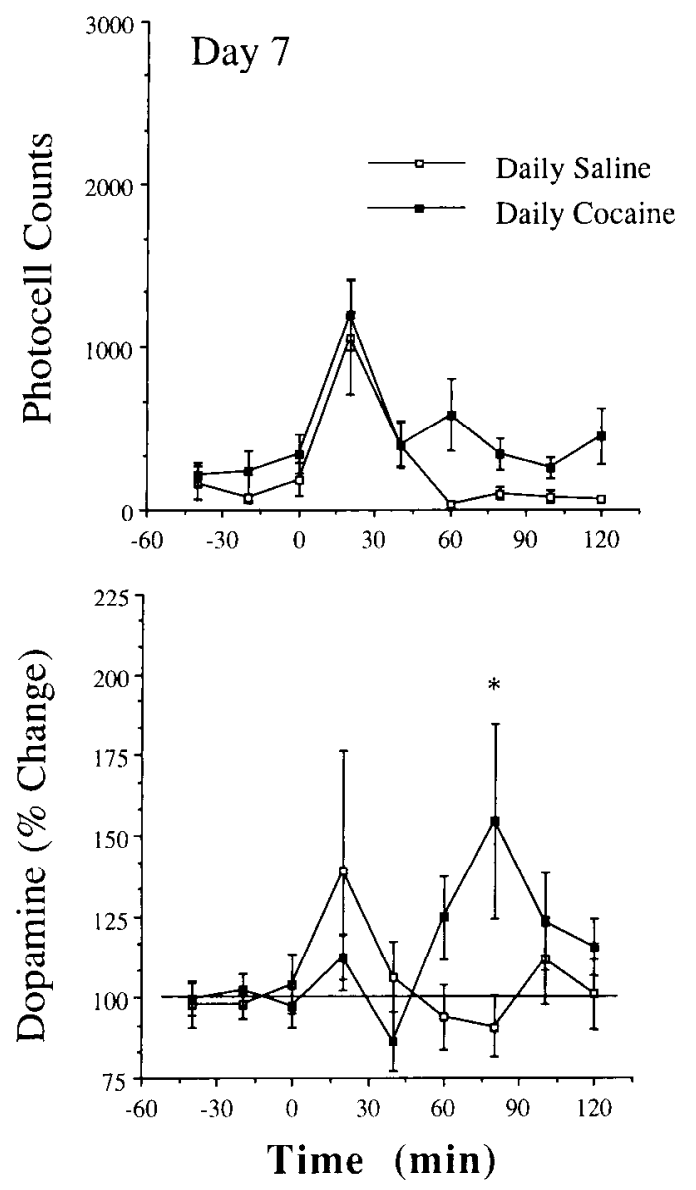

Figure 2. Effect on motor activity and extracellular dopamine content in the VTA/SN of acute saline administration made on day 7. Rats were pretreated with either daily saline $\times 6 \mathrm{~d}$ or cocaine $\times 6 \mathrm{~d}$. For dopamine values, the data were divided by the average of the three baseline measurements obtained prior to injecting saline at time 0 . The basal values were not statistically different between the cocaine ( $28 \pm$ $5 \mathrm{fmol} / \mathrm{min} ; N=8)$ and saline $(38 \pm 8 \mathrm{fmol} / \mathrm{min} ; N=7)$ treatment groups $(F=1.36, p=0.265)$. The data are shown as mean \pm SEM photocell counts or percentage change in dopamine. All data were evaluated using a two-way ANOVA with repeated measures over time. $F$ scores for behavior: pretreatment $F=5.45, p=0.030$; time $F=12.41$, $p<0.001$; interaction $F=1.86, p=0.070$. Dopamine $F$ scores: pretreatment $F=0.76, p=0.393$; time $\mathrm{F}=6.62, p<0.001$; interaction $F=2.03, p=0.046 .^{*}, p<0.05$, comparing cocaine to saline pretreatment groups at each time using a least significant difference test (Milliken and Johnson, 1984).

times after injection. The increase in motor activity produced by cocaine in rats with dialysis probes in the VTA/SN was less than that observed in rats with probes in the nucleus accumbens (e.g. see Fig. 1 in accompanying article, Kalivas and Duffy, 1992). Rats with probes in the VTA/SN demonstrated a maximum 1800 photocell counts in response to cocaine, and those with probes in the ventral striatum responded with 3500 counts. By itself, saline injection produced a moderate increase in motor activity and extracellular dopamine.

Effect of saline challenge on extracellular dopamine, groups $l$ and 2. Figure 2 shows the effect of acute saline $(1.0 \mathrm{ml} / \mathrm{kg}$, i.p.) injected on day $7,1 \mathrm{~d}$ after discontinuing daily cocaine or saline injections. Although a significant overall effect was measured between pretreatment groups on motor activity, at no individual time point did the post hoc analysis reveal a significant difference. Ilowever, it appears that the difference between
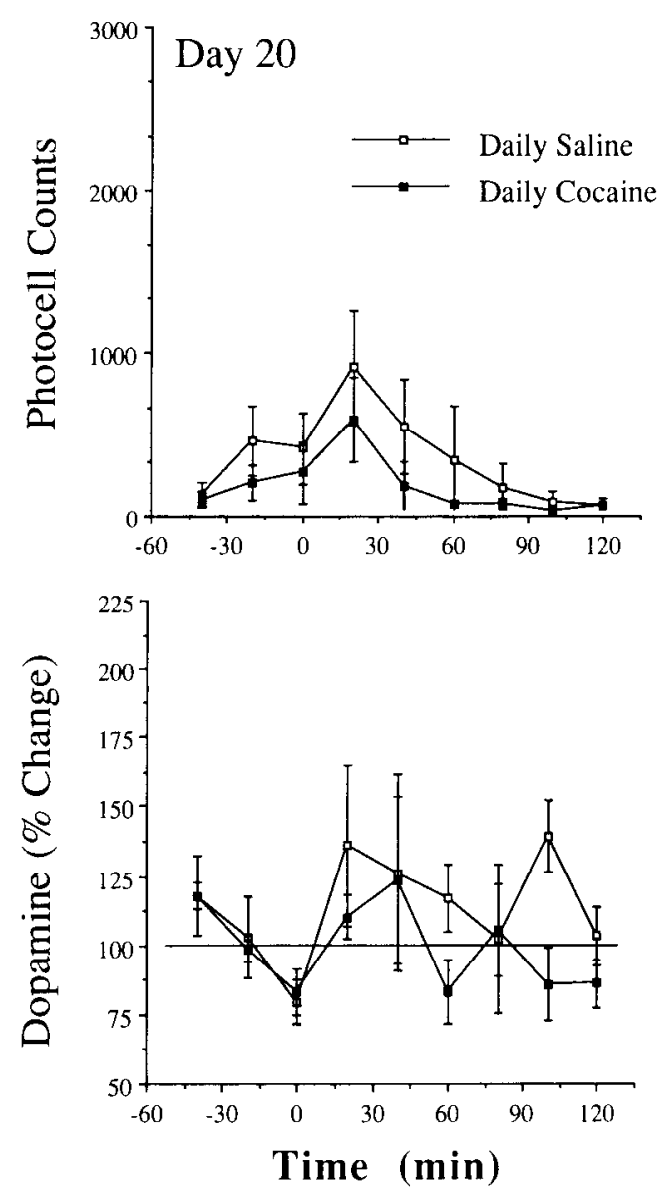

Figure 3. Effect on motor activity and extracellular dopamine content in the VTA/SN of acute saline administration made on day 20. Rats were pretreated with either daily saline $\times 6 \mathrm{~d}$ or cocaine $\times 6 \mathrm{~d}$. For dopamine values the data were divided by the average of the three baseline measurements obtained prior to injecting saline at time 0 . The basal values were not statistically different between the cocaine $(20 \pm$ $5 \mathrm{fmol} / \mathrm{min} ; N=6)$ and saline $(13 \pm 7 \mathrm{fmol} / \mathrm{min} ; N=4)$ pretreatment groups $(F=0.65, p=0.443)$. The data are shown as mean \pm SEM photocell counts or percentage change in dopamine. All data were evaluated using a two-way ANOVA with repeated measures over time. $F$ scores for behavior: pretreatment $F=0.17, p=0.693$; time $\mathrm{F}=4.12$, $p<0.001$; interaction $F=1.38, p=0.222$. Dopamine $F$ scores: pretreatment $F=9.35, p=0.016$; time $F=2.74, p=0.012$; interaction $F=1.38, p=0.225$.

the two groups resulted primarily from an elevation in photocell counts in the cocaine-pretreated rats between 60 and $120 \mathrm{~min}$ after injection of saline. This late increase in behavioral activity was associated with a similar increase in extracellular dopamine in the VTA/SN in cocaine-pretreated rats that reached statistical significance at $80 \mathrm{~min}$ after saline administration. In contrast, Figure 3 shows that on day 20 there was no difference between the cocaine and saline pretreatment groups in either photocell counts or extracellular dopamine after the acute administration of saline.

Effect of cocaine challenge on extracellular dopamine, groups 3 and 4 . Figure 4 shows the effect of acute cocaine $(15 \mathrm{mg} / \mathrm{kg}$, i.p.) given on day 7 in rats pretreated with daily saline or cocaine on days 1-6. The behavioral response to acute cocaine was significantly augmented in the rats pretreated with daily cocaine (Fig. 4, top). The augmentation was statistically significant at 20 min after injection. Likewise, Figure 4 (bottom) shows that 

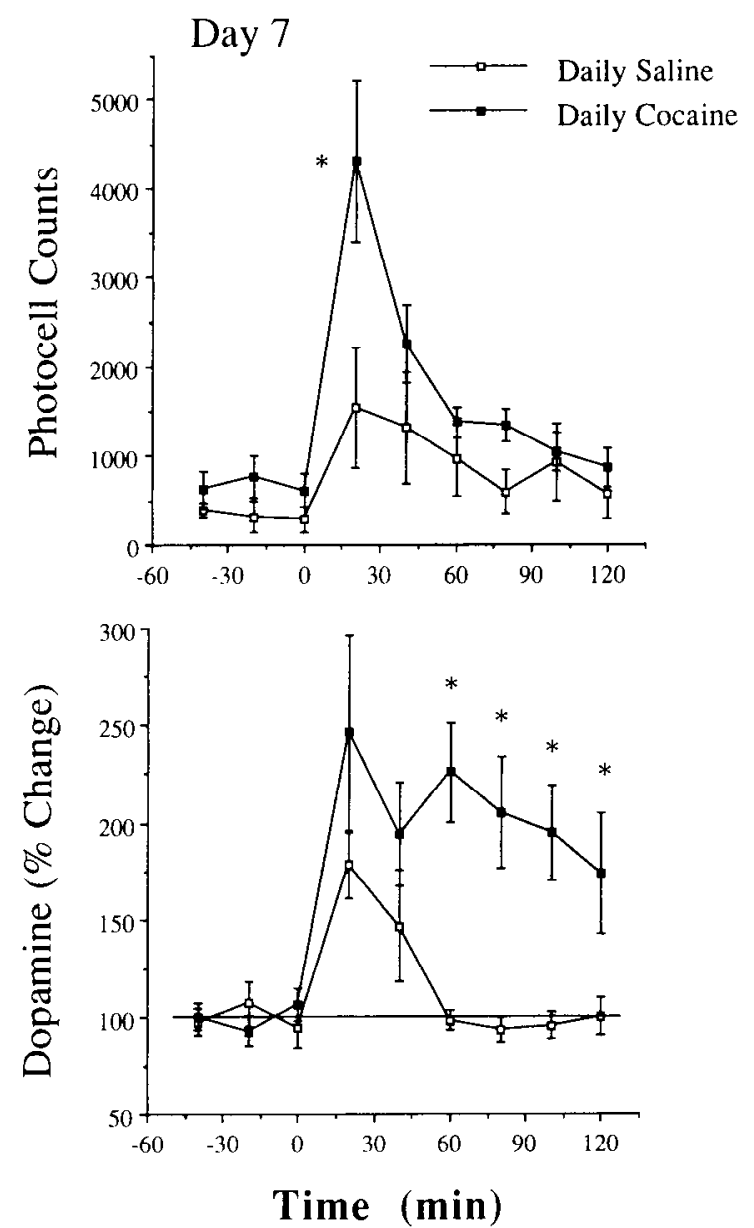

Figure 4. Effect on motor activity and extracellular dopamine content in the VTA/SN of acute saline administration made on day 7. Rats were pretreated with either daily saline $(\times 6 \mathrm{~d}, N=7)$ or cocaine $(\times 6$ $\mathrm{d}, N=8$ ). For dopamine values, the data were divided by the average of the three baseline measurements obtained prior to injecting saline at time 0 . The basal values were not statistically different between the cocaine $(36 \pm 3 \mathrm{fmol} / \mathrm{min})$ and saline $(42 \pm 8 \mathrm{fmol} / \mathrm{min})$ pretreatment groups $(F=0.51, p=0.490)$. The data are shown as mean \pm SEM photocell counts or percentage change in dopamine. All data were evaluated using a two-way ANOVA with repeated measures over time. $F$ scores for behavior: pretreatment $F=4.63, p=0.053$; time $F=12.62$, $p<0.001$; interaction $F=2.87, p=0.007$. Dopamine $F$ scores: pretreatment $F=12.94, p=0.004$; time $F=7.06, p<0.001$; interaction $F=2.69, p=0.010 .{ }^{*}, p<0.05$, comparing cocaine to saline pretreatment groups at each time using a least significant difference test (Milliken and Johnson, 1984).

the level of extracellular dopamine in the VTA/SN was enhanced in daily cocaine-pretreated rats. However, in contrast to the behavioral sensitization, the augmentation in extracellular dopamine was between 60 and $120 \mathrm{~min}$ after acute cocaine administration when motor activity had returned to control levels.

Figure 5 shows the effect of acute cocaine given on day 20 . The behavioral response to cocaine was significantly augmented in the daily cocaine pretreatment group at 20 and 40 min after injection. In contrast, no significant augmentation in extracellular dopamine was measured in the VTA/SN of daily cocainetreated rats compared to rats pretreated with daily saline injections.

Basal levels of dopamine, groups 5 and 6. Regression curves were obtained from the titration of increasing concentrations of
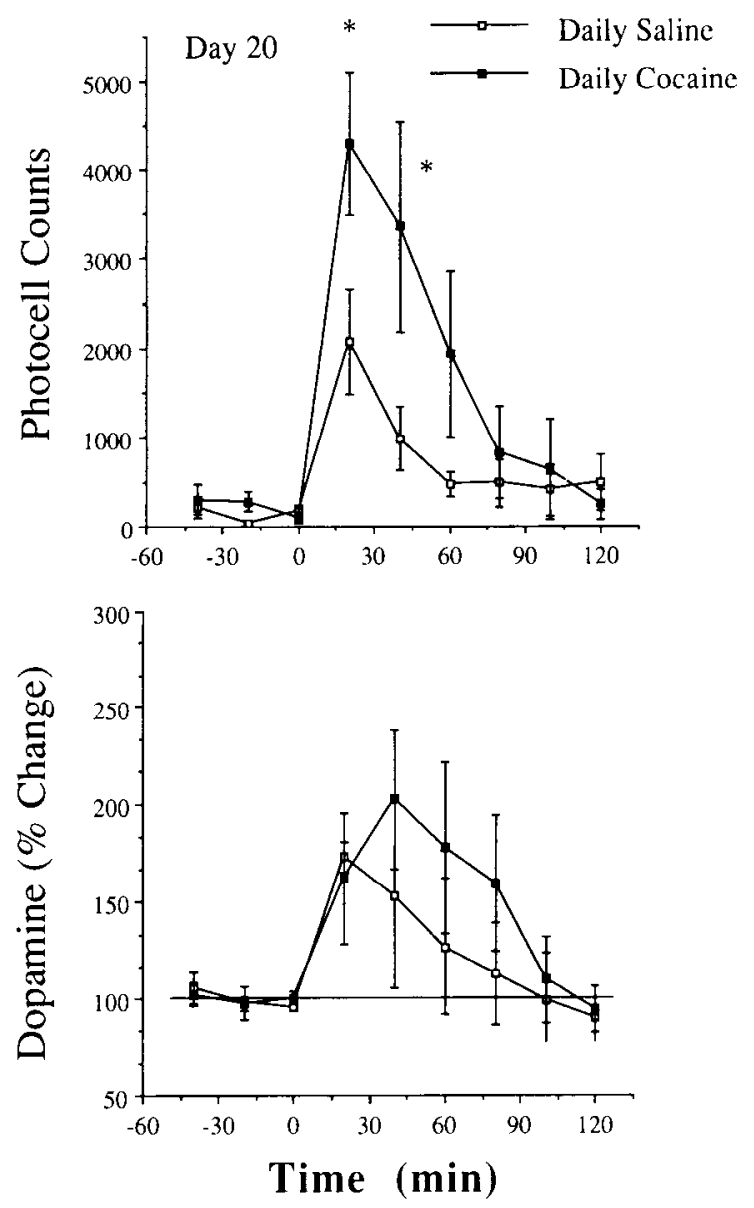

Figure 5. Effect on motor activity and extracellular dopamine content in the VTA/SN of acute cocaine administration made on day 20 . Rats were pretreated with either daily saline ( $\times 6 \mathrm{~d}, N=6)$ or cocaine $(\times 6$ $\mathrm{d}, N=8$ ). For dopamine values, the data were divided by the average of the three baseline measurements obtained prior to injecting saline at time 0 . The basal values were not statistically different between the cocaine $(38 \pm 6 \mathrm{fmol} / \mathrm{min})$ and saline $(53 \pm 17 \mathrm{fmol} / \mathrm{min})$ pretreatment groups $(F=1.62, p=0.228)$. The data are shown as mean \pm SEM photocell counts or percentage change in dopamine. All data were evaluated using a two-way ANOVA with repeated measures over time. $F$ scores for behavior: pretreatment $F=2.29, p=0.156$; time $F=14.19$, $p<0.001$; interaction $F=2.82, p=0.008$. Dopamine $F$ scores: pretreatment $F=0.58, p=0.463$; time $F=4.87, p<0.001$; interaction $F=0.63, p=0.751 .^{*}, p<0.05$, comparing cocaine to saline pretreatment groups at each time using a least significant difference test (Milliken and Johnson, 1984).

dopamine through the dialysis probe. The point of no net flux is indicative of the basal concentration of extracellular dopamine. Figure 6 shows that on day 7 the basal concentration of dopamine was significantly elevated in rats pretreated with daily cocaine compared to rats pretreated with daily saline (cocaine, $1.31 \pm 0.15 \mathrm{nM}$; saline, $0.79 \pm 0.14 \mathrm{nM} ; t_{(13)}=3.73, p<0.01$ ). There was no significant difference in the slopes of the lines (cocaine, $0.64 \pm 0.08$; saline, $0.60 \pm 0.07$ ). In contrast, on day 20 the concentration of dopamine in the cocaine-pretreated rats had returned to the values obtained in the control group (cocaine, $1.52 \pm 0.28 \mathrm{~nm}$; saline, $1.33 \pm 0.32 \mathrm{~nm}$ ). Likewise, there was no difference in the slopes (cocaine, $0.59 \pm 0.03$; saline, $0.66 \pm 0.08$ ). The correlation coefficient for the linear regression from each experiment was $>0.94$, and none of the mean correlation coefficients differed significantly for the lines shown in Figure 6. 
Figure 6. Basal extracellular concentration of dopamine in the VTA/SN determined using in vivo net flux of dopamine. Dialysis was performed on day 7 or day 20 after the rats had been pretreated with saline (group 5) or cocaine (group 6) on days 1-6. Each line was derived from six to eight animals, and the data are shown as the mean \pm SEM difference between the concentration of dopamine added to the dialysis probe in the perfusate and that collected at the probe effluent (Parsons and Justice, 1991). Zero on the y-axis is the interpolated concentration of dopamine in the perfusate at which no net flux with the extracellular fluid occurs and corresponds to the basal concentration of dopamine. Although four concentrations of dopamine $(0,1,3$, and $10 \mathrm{~nm})$ were used to generate the line, for illustrative purposes the three concentrations nearest the point of no net flux are shown. The basal concentration of dopamine was greater in cocaine-pretreated rats on day 7 (cocaine, $1.31 \pm$ $0.15 \mathrm{~nm}$; saline, $0.79 \pm 0.14 \mathrm{~nm} ; t_{(13)}=$ $3.73, p<0.01$ ), but not on day 20 (cocaine, $1.52 \pm 0.28 \mathrm{~nm}$; saline, $1.33 \pm$ $0.32 \mathrm{~nm})$. The slopes and correlation coefficients for all lines were not statistically different.

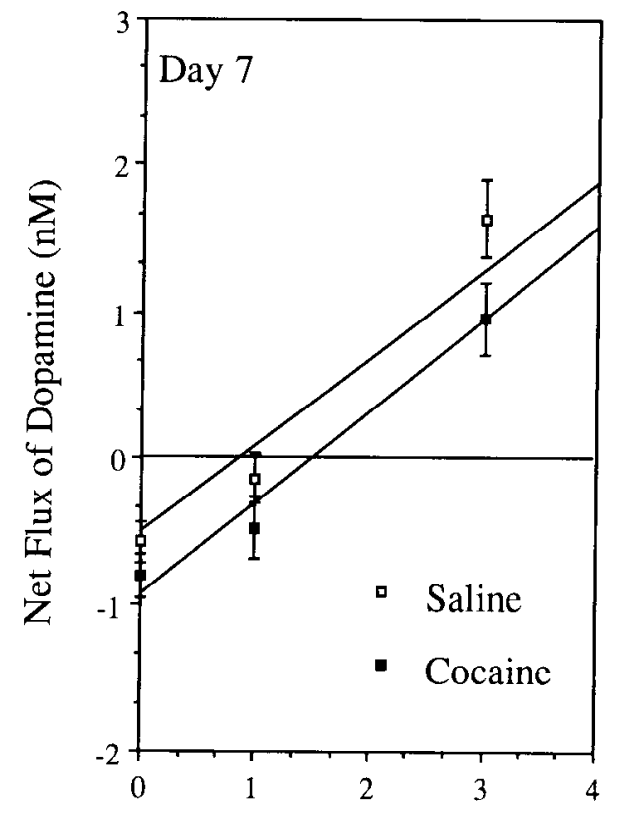

Dopamine in Perfusate (nM)

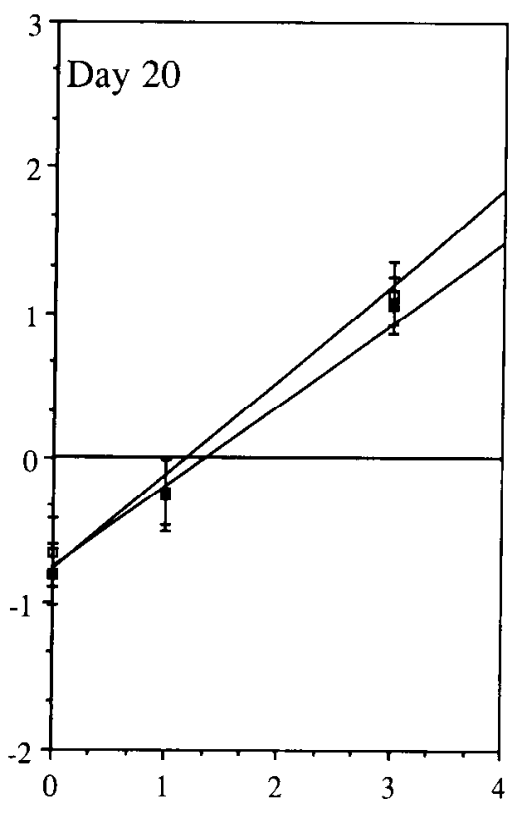

Dopamine in Perfusate (nM)
Histology. Figure 7 illustrates the location of the dialysis probes in the VTA/SN from all the experiments conducted in which animals received an acute injection of saline or cocaine (groups $1-4)$. From 72 rats, there were a total of 55 successful dialysis experiments. Eight rats died from convulsions immediately following the administration of cocaine $(30 \mathrm{mg} / \mathrm{kg}$, i.p.). No other convulsive behavior was noted. In 10 experiments, other difficultics prevented using the data, including the chronic implant coming loose, decreased flow through the dialysis probe, or chromatographic problems (coelution of dopamine with an electroactive contaminant or dopamine was below the detection limit). Three rats were excluded because the cannulas were outside the VTA/SN, which was defined as the ventral tegmental area, medial substantia nigra (within $0.5 \mathrm{~mm}$ of the ventral tegmental area), nucleus linearis, and nucleus interfascicularis (Phillipson, 1979; Swanson, 1982). The inset in Figure 7 shows a micrograph of tyrosine hydroxylase-immunoreactive neurons in the vicinity of the glial scar produced by the insertion of a dialysis probe into the VTA. Note the abundance of tyrosine hydroxylase-immunoreactive perikarya, indicating that the dialysis experiment was not neurotoxic to the tissue adjacent to the probe. However, in spite of the lack of apparent toxicity adjacent to the dialysis probe, the mechanical destruction produced by the dialysis probe may account for the relatively low behavioral response to an acute cocaine challenge in rats with probes in the VTA/SN compared to rats with dialysis probes in the nucleus accumbens (compare Fig. 1 with Fig. 1 in the accompanying article, Kalivas and Duffy, 1992).

\section{Discussion}

This study reveals that the capacity of acute cocaine to elevate extracellular dopamine content in the VTA/SN is augmented in rats behaviorally sensitized to cocaine $24 \mathrm{hr}$ after discontin- uing daily cocaine (i.e., day 7), but not after $14 \mathrm{~d}$ of withdrawal (i.e., day 20). Likewise, the basal levels of extracellular dopamine were greater in cocaine-pretreated rats at $24 \mathrm{hr}$, but not at $14 \mathrm{~d}$ after discontinuing daily injections. Also at $24 \mathrm{hr}$ but not $14 \mathrm{~d}$, extracellular dopamine was increased in response to an acute saline injection in cocaine-pretreated rats. The time course of the augmentation in cocaine-induced extracellular dopamine lcvels at $24 \mathrm{hr}$ of withdrawal did not fully parallel the behavioral response. Although the maximum in both responses occurred at $20 \mathrm{~min}$ after injection, the neurochemical response persisted for at least $120 \mathrm{~min}$ while the behavioral response returned to near baseline by $60 \mathrm{~min}$. The prolonged release indicates that the normal mechanisms for regulating somatodendritic dopamine release in the VTA/SN have been altered by repeated cocaine treatments.

One mechanism whereby repeated cocaine administration may augment the basal and cocaine-induced extracellular somatodendritic dopamine is via an alteration in inhibitory regulation of the dopamine neurons. Short-loop negative feedback is derived from the stimulation of somatodendritic $D_{2}$ autoreceptors, which inhibits dopamine cell firing (Bunney et al., 1973; Wang, 1981; White and Wang, 1984a; Kapoor et al., 1989; Kalivas and Duffy, 1991). In vivo and in vitro administration of acute cocaine have been shown to elicit $\mathrm{D}_{2}$ receptor-mediated inhibition of dopamine neurons (Einhorn et al., 1988; Brodie and Dunwiddie, 1990; Lacey et al., 1990). Systemic or in vitro exposure to cocaine or amphetamine reduces the capacity of $D_{2}$ receptor agonists to inhibit dopamine cell firing frequency (Antelman and Chiodo, 1981; White and Wang, 1984b; Kamata and Rebec, 1985; Lee et al., 1988; Henry et al., 1989; Seutin et al., 1991). Under conditions where $\mathrm{D}_{2}$ autoreceptor inhibition is diminished, the neuron would be more easily depolarized. This would result in greater activation of voltage-dependent 


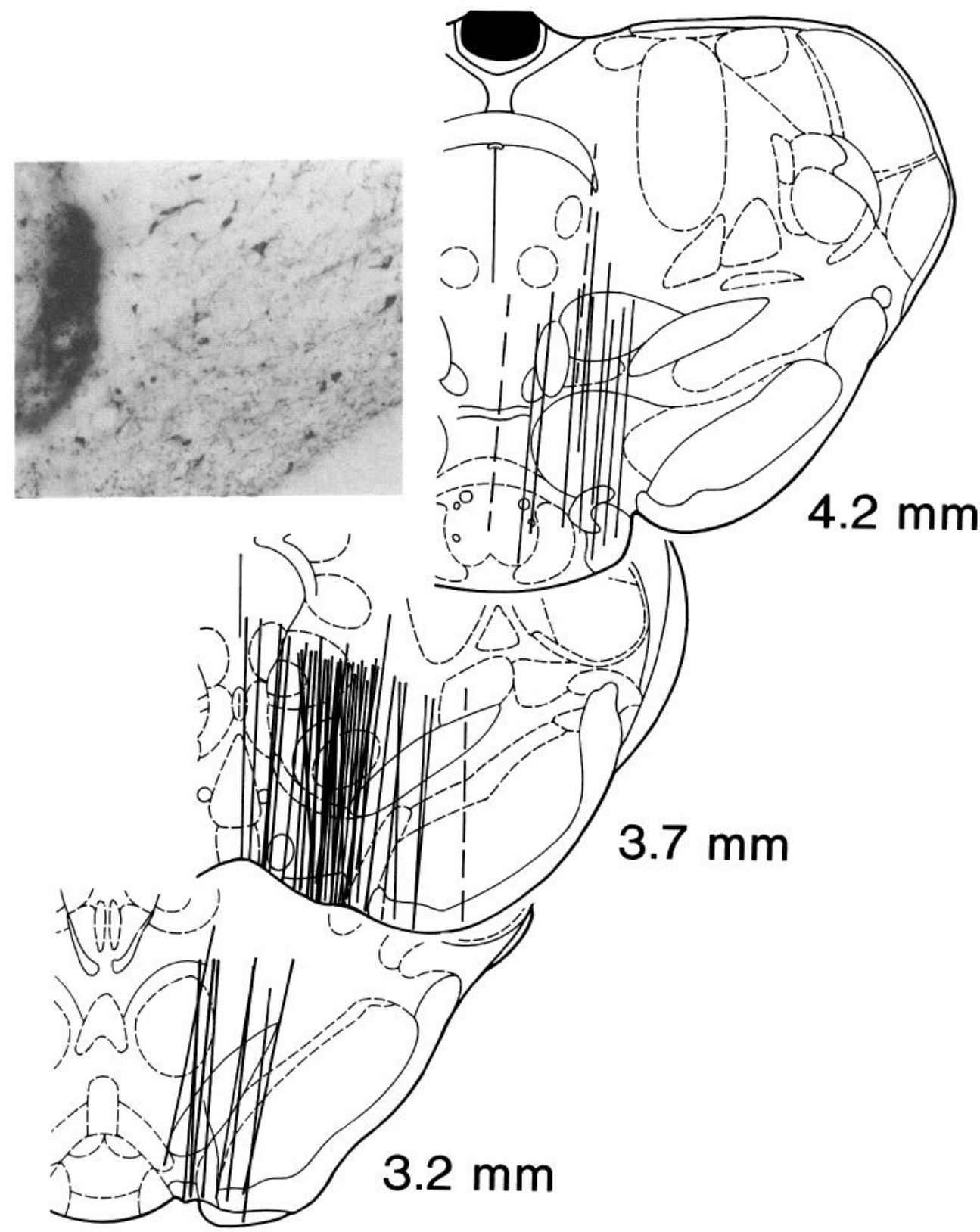

Figure 7. Location of dialysis probes in the ventromedial mesencephalon. The bottom $2.5 \mathrm{~mm}$ of each cannula track is shown. The inset shows the medial edge of the glial scar remaining 5 $\mathrm{d}$ after removing the dialysis probe from the VTA. Note the many tyrosine hydroxylase-immunoreactive neurons adjacent to the glial scar. The dashed cannula tracks correspond to probe placement outside the VTA/SN. The drawings were made according to the atlas of Paxinos and Watson (1986). calcium channels and increased calcium-dependent dopamine release (Llinas et al., 1984; Grace and Onn, 1989). Supporting $\mathrm{D}_{2}$ receptor desensitization as a mechanism for augmenting somatodendritic dopamine release, Ackerman and White (1990) demonstrated that $D_{2}$ receptor desensitization in response to repeated cocaine is transitory and not present by $8 \mathrm{~d}$ after discontinuing daily cocaine treatments, as was observed with extracellular dopamine in the VTA/SN in the present report. Furthermore, this is consistent with the finding that more spontaneously firing neurons are present and the overall firing rate is increased in the VTA of rats pretreated with daily cocaine (Henry et al., 1989). The elevation in basal levels of extracellular dopamine in the VTA after $24 \mathrm{hr}$, but not $14 \mathrm{~d}$, of withdrawal also indicates a loss of autoreceptor regulation.

In spite of $\mathrm{D}_{2}$ receptor desensitization, there is no alteration in $\mathrm{D}_{2}$ receptor density in the VTA/SN after cocaine pretreatment (Peris et al., 1990; Ziegler et al., 1991). However, $D_{2}$ receptorinduced hyperpolarization of dopamine neurons results from a pertussis toxin-sensitive G-protein coupling to an ATP-sensitive potassium channels (Innis and Aghajanian, 1987; Lacey et al., 1987), and repeated cocaine reduces the content of $\mathrm{Gi} \alpha$ and Go $\alpha$ and the pertussis toxin-catalyzed in vitro ADP-ribosylation of G-proteins in the VTA/SN (Nestler et al., 1990; Striplin and Kalivas, 1992). Supporting the possible role of G-proteins in the desensitization of the $\mathrm{D}_{2}$ receptor, the reduction in G-proteins in the VTA/SN by an acute cocaine challenge in cocainepretreated rats is transitory and not present by $14 \mathrm{~d}$ after discontinuing daily treatments (Kalivas et al., 1992). However, $\mathrm{GABA}_{\mathrm{B}}$ receptors are coupled via G-proteins to the same $\mathrm{K}^{+}$ conductance as $D_{2}$ receptors (Lacey et al., 1988), and the inhibitory effect of iontophoretic GABA is not altered in rats pretreated with daily cocaine (Henry et al., 1989). Thus, if a reduction in G-proteins is involved in $\mathrm{D}_{2}$ receptor desensitization, it is specific for $\mathrm{D}_{2}$ receptor coupling mechanisms. Alternatively, iontophoretic GABA also stimulates $\mathrm{GABA}_{\mathrm{A}}$ receptors, which hyperpolarize dopamine cells and may mask a 
reduction in $\mathrm{GABA}_{\mathrm{B}}$ receptor-mediated inhibition (Sugita et al., 1992).

In addition to $D_{2}$ receptor desensitization, it is possible that repeated cocaine may alter long-loop inhibitory feedback. Longloop negative feedback is derived from neurons in the nucleus accumbens, striatum, and pallidum that have descending GABAergic projections to the VTN SN (Walaas and Fonnum, 1980; Yim and Mogenson, 1980; Grace and Bunney, 1985; Haber et al., 1985; Smith and Bolam, 1990; Johnson et al., 1992; Sugita et al., 1992), and cocaine-induced inhibition of VTA dopamine cell firing frequency in vivo results partly from the disinhibition of GABAergic afferents (Einhorn et al., 1988). Although Henry et al. (1989) found that repeated cocaine pretreatment did not alter the capacity of iontophoretic GABA to inhibit dopamine neurons, it remains possible that GABA release may be altered by repeated cocaine treatments. One mechanism by which this could occur is via stimulation of $D_{1}$ receptors. In the substantia nigra, $D_{1}$ receptors are located primarily on nondopaminergic terminals in the ventral mesencephalon (Savasta et al., 1986; Altar and Hauser, 1987). Although a modest density of $D_{1}$ receptors was recently identified in the ventral tegmental area (Mansour et al., 1992), the cellular localization has not been experimentally evaluated. Thus, it is possible that sensitization to cocaine may be associated with an alteration in the modulation of GABA transmission by $D_{1}$ receptor stimulation (see Kalivas and Stewart, 1991, for discussion). Supporting a role for the stimulation of $D_{1}$ receptors in the initiation of behavioral sensitization to psychostimulants is the finding by Stewart and Vezina (1989) that microinjection of relatively high doses of the $\mathrm{D}_{1}$ antagonist SCH-23390 into the VTA/SN prevents behavioral sensitization produced by the systemic administration of amphetamine.

Considering the apparent importance of the stimulation of $D_{1}$ receptors in the VTA/SN in the initiation of behavioral sensitization (Stewart and Vezina, 1989), it follows that the observed increase in extracellular dopamine content in the VTA/SN of cocaine-sensitized rats is stimulating $D_{1}$ receptors. Other evidence supports a role for the VTA/SN in the initiation of behavioral sensitization to psychostimulants. The repeated microinjection of amphetamine in the VTA/SN, but not into the nucleus accumbens, results in an augmented behavioral response to a systemic challenge of amphetamine or cocaine (Hitremann et al., 1980; Dougherty and Ellinwood, 1981; Kalivas and Weber, 1988; Vezina and Stewart, 1990; Hooks et al., 1992). Also, the changes in G-protein ADP-ribosylation produced by daily cocaine administration were specific for the VTA/SN and did not occur in the nucleus accumbens, striatum, or lateral substantia nigra (Striplin and Kalivas, 1992; but see Nestler et al., 1990, who found changes in the ventral tegmental area and nucleus accumbens, but not in the substantia nigra and striatum). Although the psychostimulants act in the VTA/SN to induce behavioral sensitization, none of the alterations in $\mathrm{D}_{2}$ receptor function (Ackerman and White, 1990), G-proteins (Striplin and Kalivas, 1992), or extracellular dopamine content (present report) endure for $14 \mathrm{~d}$. In contrast, behavioral sensitization to psychostimulants persists indefinitely (Robinson and Bccker, 1986; Kalivas and Stewart, 1991). Thus, while the neurochemical and physiological alterations produced in the VTA/ SN by daily cocaine may be involved in the initiation of behavioral sensitization, they are not the permanent alterations that underlie the long-term sensitized response. A better candidate for the long-term change is the augmentation in terminal field dopamine release, which has been shown in vivo (Robinson et al., 1988; Kalivas and Duffy, 1993), and in vitro (Kolta et al., 1985; Robinson and Becker, 1986) to persist for at least $21 \mathrm{~d}$ after discontinuing repeated psychostimulant injections. Also, long-term changes in the responsiveness of neurons in the nucleus accumbens to a $D_{1}$ agonist have been documented (Henry and White, 1991).

The augmentation in the effect of acute saline on extracellular dopamine in the VTA/SN may indicate the presence of a conditioned response. Thus, the injection procedure and administration of saline were sufficient to produce a modest elevation in extracellular dopamine and photocell counts in rats pretreated with daily cocaine. Conditioning of the motor stimulant effect of psychostimulants is well documented (Tilson and Rech, 1973; Post et al., 1981; Beninger and Hahn, 1983; Beninger and Herz, 1986; Stewart and Vezina, 1988; Weiss et al., 1989). Although not apparent in the accompanying report (Kalivas and Duffy, 1992), a similar neurochemical augmentation has been observed in the ventral striatum of cocaine-pretreated rats (Kalivas and Duffy, 1990; Fontana et al., 1991; but see Brown and Fibiger, 1991).

In summary, daily cocaine pretreatment resulted in an augmented behavioral response to an acute cocaine challenge that was associated with an increase in extracellular dopamine in the VTA/SN at $24 \mathrm{hr}$, but not $14 \mathrm{~d}$ after discontinuing the daily cocaine injections. Likewise, at $24 \mathrm{hr}$ the basal extracellular concentration of dopamine was elevated in daily cocaine-pretreated rats. It is proposed that the augmented extracellular dopamine content in the VTA/SN may result from desensitization of $\mathrm{D}_{2}$ receptors. Furthermore, it is hypothesized that the augmented extracellular concentration of dopamine may increase the stimulation of $D_{1}$ receptors in the ventral mesencephalon and that this sequence of events is critical for the initiation of behavioral sensitization to psychostimulants.

\section{References}

Ackerman JM, White FJ (1990) A10 somatodendritic dopamine autoreceptor sensitivity following withdrawal from repeated cocaine treatment. Neurosci Lett 117:181-187.

Akimoto K, Hamamura T, Otsuki S (1989) Subchronic cocaine treatment enhances cocaine-induced dopamine efflux, studies by in vivo intracerebral dialysis. Brain Res 490:339-344.

Akimoto K, Hamamura T, Kazahaya Y, Akiyama K, Otsuki S (1990) Enhanced extracellular dopamine level may be the fundamental neuropharmacological basis of cross-behavioral sensitization between methamphetamine and cocaine-an in vivo dialysis study in freely moving rats. Brain Res 507:344-346.

Altar CA, Hauser K (1987) Topography of substantia nigra innervation by $D_{1}$ receptor-containing striatal neurons. Brain Res $410: 1-11$.

Antelman SM, Chiodo LA (1981) Dopamine autoreceptor subsensitivity: a mechanism common to the treatment of depression and the induction of amphetamine psychosis. Biol Psychiatry 16:717-727.

Beninger RJ, Hahn BL (1983) Pimozide blocks establishment but not expression of amphetamine-produced environment-specific conditioning. Science 220:1304.

Beninger RJ, Herz RS (1986) Pimozide blocks establishment but not expression of cocaine-produced environment-specific conditioning. Life Sci 38:1425.

Benloucif S, Galloway MP (1991) Facilitation of dopamine release in vivo by serotonin agonists: studies with microdialysis. Eur J Pharmacol 200:1-8.

Brodie MS, Dunwiddie TV (1990) Cocaine effects in the ventral tegmental area: evidence for an indirect dopaminergic mechanism of action. Naunyn Schmiedebergs Arch Pharmacol 342:660-665.

Brown EE, Fibiger HC (1991) Cocaine-induced conditioned locomotion: lack of in vivo evidence for associated conditioned neurochemical events. Soc Neurosci Abstr 17:566.15. 
Bunney BS, Walters JR, Roth RH, Aghajanian GK (1973) Dopaminergic neurons: effect of antipsychotic drugs and amphetamine on single cell activity. J Pharmacol Exp Ther 185:560-571.

Dougherty GG Jr, Ellinwood EH Jr (1981) Chronic $d$-amphetamine in nucleus accumbens: lack of tolerance or reverse tolerance of locomotor activity. Life Sci 28:2295-2298.

Einhorn LC, Johansen PA, White FJ (1988) Electrophysiological effects of cocaine in the mesoaccumbens dopamine system: studies in the ventral tegmental area. J Neurosci 8:100-112.

Fallon JH, Moore RY (1978) Catecholamine innervation of basal forebrain. IV. Topography of the dopamine projection to the basal forebrain and striatum. J Comp Neurol 180:545-580.

Fontana DJ, Post RM, Pert A (1991) Conditioned increases in mesolimbic dopamine overflow by stimuli associated with cocainc. Soc Neurosci Abstr 17:268.4.

Grace AA, Bunney BS (1985) Opposing effects of striatonigral feedback pathways on midbrain dopamine cell activity. Brain Res 333:271284.

Grace AA, Onn S-P (1989) Morphology and electrophysiological properties of immunocytochemically identified rat dopamine neurons recorded in vitro. J Neurosci 9:3463-3481.

Haber SN, Groenwegen HJ, Grove EA, Nauta WJH (1985) Efferent connections of the ventral pallidum: evidence of a dual striatopallidofugal pathway. J Comp Neurol 235:322-335.

Henry DJ, White FJ (1991) Repeated cocaine administration causes persistent enhancement of D1 dopamine receptor sensitivity within the rat nucleus accumbens. J Pharmacol Exp Ther 258:882-890.

Henry DJ, Margarct AG, Whitc FJ (1989) Electrophysiological effects of cocaine in the mesoaccumbens dopamine system: repeated administration. J Pharmacol Exp Ther 251:833-839.

Hitzemann R, Wu J, Hom D, Loh H (1980) Brain locations controlling the behavioral effects of chronic amphetamine intoxication. Psychopharmacology 72:93-101

Hooks MS, Jones H, Liem BJ, Justice JB Jr (1992) Sensitization and individual differences to ip amphetamine or cocaine following repeated intra-cranial amphetamine infusions. Ann NY Acad Sci 654: $444-447$.

Innis RB, Aghajanian GK (1987) Pertussis toxin blocks autoreceptormediated inhibition of dopaminergic neurons in rat substantia nigra Brain Res 411:139-143.

Johnson SW, Mercuri NB, North RA (1992) 5-Hydroxytryptamine $e_{1 B}$ receptors block the $\mathrm{GABA}_{\mathrm{B}}$ synaptic potential in rat dopamine neurons. J Neurosci 12:2000-2006.

Kalivas PW, Duffy P (1990) The effect of acute and daily cocaine treatment on extracellular dopamine in the nucleus accumbens. Synapse 5:48-58.

Kalivas PW, Duffy P (1991) Comparison of somatodendritic and axonal mesolimbic dopamine release using in vivo dialysis. J Neurochem 56:961-967.

Kalivas PW, Duffy P (1993) Time course of extracellular dopamine and behavioral sensitization to cocaine. I. Dopamine axon terminals. J Neurosci 13:266-275.

Kalivas PW, Stewart J (1991) Dopamine transmission in drug- and stress-induced behavioral sensitization. Brain Res Rev 16:223-244.

Kalivas PW, Weber B (1988) Amphetamine injection into the A10 dopamine region sensitizes rats to peripheral amphetamine and cocaine. J Pharmacol Exp Ther 245:1095-1102.

Kalivas PW, Striplin C, Steketee J, Klitenick M, Duffy P (1992) Cellular mechanisms of behavioral sensitization to drugs of abuse. Ann NY Acad Sci 654:128-135.

Kamata K, Rebec GV (1985) Iontophoretic evidence for subsensitivity of postsynaptic dopamine receptors following long-term amphetamine administration. Eur J Pharmacol 106:393-397.

Kapoor R, Webb C, Greenfield SA (1989) Endogenous dopamine modifies electroresponsiveness of pars compacta cells in the guinea pig substantia nigra in vitro. Exp Brain Res 74:653-657.

Kazahaya Y, Akimoto K, Saburo O (1989) Subchronic methamphetamine treatment enhances methamphetamine- or cocaine-induced dopamine efflux in vivo. Biol Psychiatry 25:903-912.

Kolta MG, Shreve P, De Souza V, Uretsky NJ (1985) Time course of the development of the enhanced behavioral and biochemical responses to amphetamine after pretreatment with amphetamine. Neuropharmacology 24:823-829.

Lacey MG, Mercuri NB, North RA (1987) Dopamine acts at $D_{2}$ receptors to increase potassium conductance in neurons of the rat substantia nigra. J Physiol (Lond) 392:397-416.
Lacey MG, Mercuri NB, North RA (1988) On the potassium conductance increase activated by GABAB and dopamine receptors in rat substantia nigra neurones. J Physiol (Lond) 401:437-454.

Lacey MG, Mercuri NB, North RA (1990) Actions of cocaine on rat dopaminergic neurons in vitro. Br J Pharmacol 99:731-735.

Lee TH, Ellinwood EH Jr, Nishita JK (1988) Dopamine receptor sensitivity changes with chronic stimulants. Ann NY Acad Sci 537: 324-329.

Llinas R, Greenfield SA, Jahnsen H (1984) Electrophysiology of pars compacta cells in the in vitro substantia nigra: a possible mechanism for dendritic release. Brain Res 294:127-132.

Lonroth P, Janson PA, Smith U (1987) A microdialysis method allowing characterization of intercellular water space in humans. Am J Physiol 253:E228-E231.

Mansour A, Meador-Woodruff JH, Zhou Q, Civelli O, Akil H, Watson SJ (1992) A comparison of Dl receptor binding and mRNA in rat brain using receptor autoradiographic and in situ hybridization techniques. Neuroscience 46:959-971.

Milliken GA, Johnson DE (1984) Analysis of messy data, Vol I, Designed experiments. Belmont, CA: Lifetime Learning.

Nestler EJ, Terwilliger RZ, Walker JR, Sevarino KA, Duman RS (1990) Chronic cocaine treatment decreases levels of the $G$ protein subunits $G_{i \alpha}$ and $G_{o x x}$ in discrete regions of rat brain. $J$ Neurochem 55:10791082.

Parsons I.H, Justice JB Jr (1991) Quantitative neurotransmitter microdialysis: extracellular dopamine in the nucleus accumbens. J Neurochem 58:212-218.

Parsons LH, Smith AD, Justice JB Jr (1991) Basal extraccllular dopamine is decreased in the rat nucleus accumbens during abstinence from chronic cocaine. Synapse 9:60-65.

Patrick SL, Thompson TL, Walker JM, Patrick RL (1991) Concomitant sensitization of amphetamine-induced behavioral stimulation and in vivo dopamine release from rat caudate nucleus. Brain Res 538:343-346.

Paxinos G, Watson C (1986) The rat brain in stereotaxic coordinates, $2 \mathrm{~d}$ ed. New York: Academic.

Pellegrino LK, Pellegrino AS, Cushman AJ (1979) A stereotaxic atlas of the rat brain. New York: Plenum.

Peris J, Boyson SJ, Cass WA, Curella P, Dwoskin LP, Larson G, Lin L-H, Yasuda RP, Zahniser NR (1990) Persistence of neurochemical changes in dopamine systems after repeated cocaine administration. J Pharmacol Exp Ther 253:38-44.

Pettit HO, Pan H-T, Parsons LH, Justice JB Jr (1990) Extracellular concentrations of cocaine and dopamine are enhanced during chronic cocaine administration. J Neurochem 55:798-804.

Phillipson OT (1979) The cytoarchitecture of the interfascicular nucleus and the ventral tegmental area of Tsai in the rat. J Comp Neurol 187:85-98.

Post RM, Lockfeld A, Squillace KM, Contel NR (1981) Drug environment interaction: context dependency of cocainc induced behavioral sensitization. Life Sci 28:755-760.

Robinson TE (1991) The neurobiology of amphetamine psychosis: evidence from studies with an animal model. In: Taniguchi symposia on brain sciences, Vol 14, Biological basis of schizophrenic disorders (Nakazawa T, ed), pp 185-201. Tokyo: Japan Scientific Societies.

Robinson TE, Becker JB (1986) Enduring changes in brain and behavior produced by chronic amphetamine administration: a review and evaluation of animal models of amphetamine psychosis. Brain Res Rev 11:157-198.

Robinson TE, Whishaw IQ (1988) Normalization of extracellular dopamine in striatum following recovery from a partial unilateral 6-OHDA lesion of the substantia nigra: a microdialysis study in freely moving rats. Brain Res 450:209-224.

Robinson TE, Jurson PA, Bennett JA, Bentgen KM (1988) Persistent sensitization of dopamine neurotransmission in ventral striatum (nucleus accumbens) produced by prior experience with $(+)$-amphetamine: a microdialysis study in freely moving rats. Brain Res 462: 211-222.

Savasta M, Dubois A, Benavides J, Scatton B (1986) Different neuronal location of $\left[{ }^{3} \mathrm{H}\right] \mathrm{SCH} 23390$ binding sites in pars reticulata and pars compacta of the substantia nigra. Neurosci Lett 72:265-271.

Seutin V, Verbanck P, Massolte L, Dresse A (1991) Acute amphetamine-induced subsensitivity of $A_{10}$ dopamine autoreceptors in vitro. Brain Res 558:141-144

Smith Y, Bolam JP (1990) The output neurones and the dopaminergic 
neurones of the substantia nigra receive a GABA-containing input from the globus pallidus in the rat. J Comp Neurol 296:47-64.

Stewart J, Vezina P (1988) Conditioning and behavioral sensitization In: Sensitization in the nervous system (Kalivas PW, Barnes CD, eds), pp 207-224. Caldwell, NJ: Telford.

Stewart J, Vezina P (1989) Microinjections of SCH-23390 into the ventral tegmental area and substantia nigra pars reticulata attenuate the development of sensitization to the locomotor activating effects of systemic amphetamine. Brain Research 495:401-406.

Striplin CD, Kalivas PW (1992) Correlation between behavioral sensitization to cocaine and $G$ protein ADP-ribosylation in the ventral tegmental area. Brain Res 579:181-186.

Sugita S, Johnson SW, North RA (1992) Synaptic inputs to GABA and $\mathrm{GABA}_{\mathrm{B}}$ receptors originate from discrete afferent neurons. Neurosci Lett 134:207-211.

Swanson LW (1982) The projections of the ventral tegmental area and adjacent regions: a combined fluorescent retrograde tracer and immunofluorescence study in the rat. Brain Res Bull 9:321-353.

Tilson HA, Rech RH (1973) Conditioned drug effects and absence of tolerance to $d$-amphetamine induced motor activity. Pharmacol Biochem Behav 1:149-153.

Vezina P, Stewart J (1990) Amphetamine administered into the ventral tegmental area but not to the nucleus accumbens sensitizes rats to systemic morphine: lack of conditioned effects. Brain Res 516:99106.
Walaas I, Fonnum F (1980) Biochemical evidence of $\gamma$-aminobutyrate containing fibres from the nucleus accumbens to the substantia nigra and ventral tegmental area in the rat. Neuroscience 5:63-72.

Wang RY (1981) Dopaminergic neurons in the rat ventral tegmental area. II. Evidence for autoregulation. Brain Res Rev 3:141-152.

Weiss SR B, Post RM, Pert A, Woodward R, Murman D (1989) Context-dependent cocaine sensitization: differential effect of haloperidol on development versus expression. Pharmacol Biochem Behav 34: 655-661.

White FJ, Wang RY (1984a) Pharmacological characterization of dopamine autoreceptors in the rat ventral tegmental area: microiontophoretic studies. J Pharmacol Exp Ther 231:275-280.

White FJ, Wang RY (1984b) Al0 dopamine neurons: role of autoreceptors in detemining firing rate and sensitivity to dopamine agonists. Life Sci 34:1161-1170.

Yim CY, Mogenson GJ (1980) Effect of picrotoxin and nipecotic acid on inhibitory response of dopaminergic neurons in the ventral tegmental area to stimulation of the nucleus accumbens. Brain Res 199. $466-472$.

Yoshikawa T, Shibuya H, Kaneno S, Toru M (1991) Blockade of behavioral sensitization to methamphetamine by lesion of hippocampo-accumbal pathway. Life Sci 48:1325-1332.

Zeigler S, Lipton J, Toga A, Ellison G (1991) Continuous cocaine administration produces persisting changes in brain neurochemistry and behavior. Brain Res 552:27-35. 